\title{
Pandemia, crisis estructural y después ¿qué? \\ Debates sobre desarrollo socioeconómico, territorio y economías alternativas
}

Pandemics, structural crisis and then ¿what? Debates on socioeconomic development, territory, and alternative economies

Pandemia, crise estrutural e depois? Discussões sobre desenvolvimento socioeconômico, território e economias alternativas

\section{Rodolfo Pastore ${ }^{1}$}

Recibido: 10 de junio de 2020 Aprobado: 1 de diciembre de 2020

Publicado: 12 de enero de 2021

Cómo citar este artículo: Pastore, R. (2021). Pandemia, crisis estructural y después ¿qué? Debates sobre desarrollo socioeconómico, territorio y economías alternativas.

Cooperativismo \& Desarrollo, 29(119), 1-31. doi: https://doi.org/10.16925/2382-4220.2021.01.10

Artículo de investigación. https://doi.org/10.16925/2382-4220.2021.01.10

1 Docente-investigador de la Universidad Nacional de Quilmes (UNQ). Director del Departamento de Economía y Administración y del Programa CREES (Construyendo Redes Emprendedoras en Economía Social) de la UNa.

Correo electrónico: rpastore@unq.edu.ar 
2 Pandemia, crisis estructural y después ¿qué? Debates sobre desarrollo socioeconómico, territorio y economías alternativas

\title{
Resumen
}

El presente artículo hace un análisis de los problemas socioeconómicos y las brechas de desigualdad que generan, para resaltar la importancia de los procesos asociativos, así como la expansión económica. Lo anterior, con ánimo de fortalecer no solo el ámbito económico, sino cultural y social, con especial énfasis en el desarrollo territorial. La investigación es cualitativa, reflexiva y analítica, exponiendo diferentes posturas políticas, sociales y económicas. Los principales aportes giran en torno al análisis de los problemas socioeconómicos, que surgieron con ocasión de la pandemia, a partir de los cuales se presenta la necesidad de proponer fortalecimientos en esta materia, es decir, la economía, pero no solo entre la sociedad civil, sino entre entidades gubernamentales y organismos internacionales. Finalmente, se propone una reflexión en torno al desarrollo territorial y la expansión de economías que resulten ser solidarias y transformadoras de forma tal que generen sostenibilidad en la vida.

Palabras clave: desarrollo sostenible, desarrollo territorial, economías alternativas, cooperativismos, economía popular.

\section{Descriptores}

P25 Economía urbana, rural y regional

P42 Empresas productivas

Q01 Desarrollo sostenible

\section{Resumo}

Este artigo analisa os problemas socioeconômicos e as lacunas de desigualdade que eles geram para destacar a relevância dos processos associativos, bem como da expansão econômica. Visa fortalecer não só a dimensão econômica, mas também cultural e social, com ênfase especial no desenvolvimento dos territórios. A pesquisa é qualitativa, reflexiva e analítica, expondo diferentes posicionamentos políticos, sociais e econômicos. As principais contribuições giram em torno da análise das questões socioeconômicas que foram levantadas em função da pandemia, a partir da qual se propõe a necessidade de atender o tema, não apenas na sociedade civil, mas em entidades intergovernamentais e instituições internacionais. Por fim, propõe-se uma reflexão sobre o desenvolvimento dos territórios e a expansão das economias solidárias que transformam e geram sustentabilidade à vida.

Palavras-chave: desenvolvimento sustentável, desenvolvimento do território, economias alternativas, cooperativismo, economia popular.

\begin{abstract}
This article analyzes socioeconomical problems and the inequality gaps they generate to highlight the relevance of associative processes, as well as economic expansion. This is aimed at strengthening not only the economical dimension, but also the cultural and social one, with a special emphasis in the development of territories. The research is qualitative, reflexive, and analytical, exposing different political, social, and economic positions. Main contributions revolve around the analysis of socioeconomic issues that were raised due the pandemic, from which it is proposed necessary to attend the subject, not only within civil society, but within intergovernmental entities and international institutions. Lastly, a reflection is proposed on the development of territories and the expansion of solidary economies that transform and generate sustainability of life.
\end{abstract}

Keywords: sustainable development, territory development, alternative economies, cooperativism, popular economy. 


\section{Introducción}

De manera elocuente, se ha señalado que el virus sars-cov-2 refleja y profundiza la crisis global de las sociedades contemporáneas, como una especie de espejo que amplía o acelera, según los casos, sus principales problemas (Chul Han, 2021). En lo que concierne a los temas de este trabajo, el escenario abierto por la pandemia muestra problemas socioeconómicos estructurales que afectan sustantiva y desigualmente a las poblaciones y los territorios de distintas regiones del mundo, pero más aún a los de América Latina.

En tal sentido, la Comisión Económica para América Latina (CEPAL) revela que, lamentablemente, durante el 2020 hemos sido la región más afectada por la COVID-19 con el aciago dato de contar con el $28 \%$ de los fallecidos por esta causa a nivel mundial, cuando la región sólo representa el 8,4\% de su población (CEPAL, 2021). Pero, además, para la CEPAL, la pandemia ha puesto de manifiesto y profundizado los problemas estructurales de desigualdad, informalidad, pobreza y desprotección social que caracterizan a nuestras sociedades, con sustanciales aumentos en los niveles de vulnerabilidad social y de precariedad laboral'. Todo esto hubiera sido más grave aún de no haberse implementado medidas públicas como las transferencias de ingresos a los hogares, que en el caso de la región alcanzaron al 49\% de la población durante el 2020; aunque, al mismo tiempo, dichas medidas han sido insuficientes en un contexto de abrupta caída del PBI (-7.7\%) y de un masivo cierre de empresas, calculado en 2,7 millones (CEPAL, 2021).

En otros términos, junto a la pandemia salieron a la luz problemas socioeconómicos estructurales en nuestros países, tales como el aumento de la pobreza y el desempleo, la degradación socioambiental y del hábitat, o la desvalorización de las actividades fundamentales para la sostenibilidad de la vida, como la alimentación, la salud o el cuidado, entre las principales en el contexto de pandemia. No es difícil vincular esta problemática con la acentuada desigualdad económica, social, racial y de géneros que atraviesan nuestros territorios, con las estructuras asimétricas de

1 En dicho informe sobre el "Panorama Social de América Latina 2020", cepal (2021) indica que para ese año en la región hay 22 millones más de personas en situación de pobreza, alcanzando un total de 209 millones, afectando, en mayor medida, a mujeres, niños, indígenas, afrodescendientes y demás personas con menores niveles educativos. Por su parte, el aumento de la vulnerabilidad fue aún mayor, alcanzando una cifra de 491 millones de personas que viven con ingresos inferiores a la línea de pobreza. Esto se relaciona con el incremento del desempleo, pues se alcanzó una tasa de desocupación promedio del $10,7 \%$, que aqueja mucho más a mujeres, personas con trabajos precarios, jóvenes y migrantes. Asimismo, también creció la desigualdad, con un índice de Gini que se incrementó en un 2,9\% en relación con el 2019, número que se hubiera duplicado sin las transferencias públicas realizadas. 
4 Pandemia, crisis estructural y después ¿qué? Debates sobre desarrollo socioeconómico, territorio y economías alternativas

poder y con el predominio de lógicas económicas especulativas, neoextractivistas y de acumulación por desposesión, por parte de grandes poderes trasnacionales o locales que, en ciertos casos, llegan a la ocupación territorial violenta o al desplazamiento poblacional forzado de amplias comunidades.

De allí que la pandemia pone en evidencia, y no solo en América Latina, la necesidad de avanzar en políticas y estrategias de desarrollo socioeconómico orientadas a garantizar derechos para la sostenibilidad de la vida. Nos referimos en particular a los derechos de la naturaleza y a los derechos económicos, sociales y culturales (DESC), entre los cuales sobresalen, en este particular contexto: la salud y la atención a los cuidados; el acceso alimentario y los circuitos de cercanía; las condiciones de vivienda, hábitat, movilidad y transporte; la educación y su vinculación con la inclusión digital; y los sistemas de recolección y reciclado de residuos. En síntesis, y en términos más acuciantes para nuestros países, las condiciones de vida, trabajo e ingresos de la mayoría de la población, en particular, de las personas que se ganan la vida en trabajos de la economía popular, urbana y rural, designada muchas veces, de manera debatible, como economía informal.

Asociado a esta problemática, en los últimos años se han extendido planteamientos a favor de un cambio profundo del modelo de desarrollo imperante, señalando, al mismo tiempo, la necesidad de considerar de mejor manera la emergente diversidad de formas económicas alternativas, entre las que se incluyen las trayectorias empíricas tanto de la llamada economía social y solidaria (ESS) como la economía popular (EP) o comunitaria. Hoy, dichas ideas no solo forman parte de los ámbitos vinculados al pensamiento crítico o los movimientos sociales y populares transformadores, sino que también están presentes en proposiciones de instituciones internacionales y son parte también de una agenda de renovación de los enfoques sobre el desarrollo territorial, más allá de la distancia existente entre estos planos de debate y las acciones efectivas al respecto.

En tal sentido, este trabajo se propone realizar un paneo sintético de algunos de esos planteamientos en el debate sobre la crisis del modelo de desarrollo dominante y sobre las potencialidades alternativas de economía y desarrollo territorial, en particular en lo relacionado con la ESS y la EP. Para ello, en seguida repasamos algunos documentos de interés vinculados a organismos internacionales, tanto de orden mundial como regional. Luego, abordamos otro mensaje internacional de peso: las ideas del Papa Francisco sobre la crisis actual y su reivindicación de la economía popular. Posteriormente, hacemos lo propio con consideraciones provenientes de la renovación de los enfoques del desarrollo territorial, en particular, en su vinculación con la ESs. Finalmente, concluimos con algunas reflexiones, que buscan complejizar 
el análisis de la cuestión, recuperando una perspectiva crítica y, a la vez, propositiva sobre el tema.

\section{Organismos multilaterales, desarrollo sostenible y ESS}

Entre los documentos de organismos internacionales con interés para el tema, se encuentra el reciente informe del Secretario General de Naciones Unidas (Organización de las Naciones Unidas [ONU], 2021) para el $59^{\circ}$ periodo de sesiones de la "Comisión de Desarrollo Social", donde se defiende el carácter insostenible de las modalidades imperantes de producción y consumo, así como la necesidad de avanzar en una "transición socialmente justa hacia el desarrollo sostenible", esto es hacia un desarrollo más inclusivo, equitativo y resiliente. El Informe resalta las graves consecuencias económicas y sociales de la CovID-19, pues "no solo ha sacado a la luz las desigualdades preexistentes y la debilidad de los sistemas actuales, sino que también las ha acentuado" (ONU, 2021, p. 41)². Desde una perspectiva económica sustantiva, indica que dicha transición conlleva repensar la actividad económica no como un fin en sí, "sino como un medio para promover de manera sostenible el bienestar y las capacidades de los seres humanos, sin menoscabo del medio ambiente" (ONU, 2021, p. 41). De allí que postula repensar los marcos de políticas socioeconómicas existentes, con el objetivo que "la mejora sostenible del nivel de vida y el bienestar de todas las personas" (ONU, 2021, p. 45) se convierta en un aspecto esencial de las iniciativas que se emprendan. Para ello, pone a la cuestión social en el centro de la propuesta, señalando que es clave otorgar el protagonismo a las personas, afianzar su resiliencia social, invertir en las capacidades de las mismas y sus comunidades, al tiempo que reforzar las políticas de protección social que amplíen la cobertura a todas y todos los trabajadores, más allá de su relación y condición laboral. De acuerdo con esto, se propone que desde las políticas públicas se reorienten los incentivos económicos y de innovación hacia dichas acciones, considerando en particular "los modelos de producción y consumo centrados en las personas y respetuosos con el planeta" (ONU, 2021, p. 38), entre los cuales citan los planteamientos de la economía

2 Según el Informe, más de más de dos tercios (71 \%) de la población mundial reside en países en los que ha aumentado la desigualdad entre 1990 y la actualidad, resultando que el $10 \%$ de los adultos más ricos concentran del $55 \%$ al $75 \%$ de la riqueza mundial, mientras que más de la mitad del planeta más pobre (54 \%) posee menos del $2 \%$ de la misma. Otro dato es que cerca de 2000 millones de personas en el mundo carecen de acceso habitual a alimentos sanos, nutritivos y suficientes. 
6 Pandemia, crisis estructural y después ¿qué? Debates sobre desarrollo socioeconómico, territorio y economías alternativas

ecológica, de la economía circular y, de particular interés para este trabajo, de la ESS. El informe argumenta que la economía social y solidaria encarna otro modelo alternativo de crecimiento que busca un nuevo equilibrio entre la eficiencia económica y la resiliencia social y ambiental, y sostiene que al empoderar a las personas con mayor participación e igualdad en los procesos decisorios y en la distribución de recursos, dicha economía "fomenta el dinamismo económico, la protección social y ambiental y el empoderamiento sociopolítico" (ONU, 2021, p. 41).

En este plano, conviene señalar que, desde hace un tiempo, la Ess tiene un lugar de interés en los planteamientos e iniciativas de la oNU. De hecho, en 2013 se creó en su seno un espacio de trabajo interinstitucional permanente sobre economía social y solidaria, la United Nations Inter-Agency Task Force on Social and Solidarity Economy (UNTFSSE), al considerarse que no se estaba prestando suficiente atención al aporte clave de la misma para avanzar en los objetivos del desarrollo sostenible. A partir de entonces, la UNTFSSE tiene los siguientes objetivos: a) contribuir a aumentar la visibilidad y reconocimiento de las empresas y organizaciones de la Ess para el desarrollo sostenible; b) promover el intercambio de conocimientos y las redes en la cuestión; c) apoyar el desarrollo de un entorno institucional y normativo favorable; d) propiciar la coordinación de esfuerzos interinstitucionales y las asociaciones internacionales. Actualmente, el espacio cuenta con 18 representantes de organismos vinculados a ONU y a OCDE, junto con 14 observadores en representación de organizaciones de la sociedad civil. El grupo tiene una Secretaría General rotatoria, la cual ha estado a cargo de la Organización Internacional del Trabajo (OIT) en más de una oportunidad, como sucede en el presente.

En el mismo sentido, los ámbitos específicos de la orT en el tema sostienen la necesidad un paradigma "alternativo o complementario de desarrollo", considerando a la ESs como "una solución viable para reequilibrar los objetivos económicos, sociales y medioambientales" (OIT, s.f.a, párr. 1). Al respecto, cabe mencionar que la oıT tiene una larga tradición en cuestiones vinculadas al cooperativismo y la ESs, entre las que se destacan la creación de la unidad de cooperativas en 1920, la Recomendación 193 (2002) sobre la "Promoción de cooperativas", así como las referencias a las mismas y a la ESs en las declaraciones sobre la "Justicia social para una globalización equitativa" (OIT, 2008) y en la referente al "El futuro del trabajo" (OIT, 2019).

Asimismo, desde el 2010 funciona la Academia sobre ESS de la OIT, como espacio interregional de encuentro, formación e intercambio de experiencias de profesionales y legisladores del mundo, que tiene como objetivos contribuir a una mejor comprensión de la ESS, a reflexionar sobre su relevancia como alternativa de desarrollo en relación con el trabajo decente de la OIT, y a reforzar su impacto mediante la 
generación de una comunidad de prácticas. La primera Academia se efectuó en dicho año y, desde entonces, ya se han realizado 11 encuentros hasta el inicio de la pandemia. A su vez, en relación con la Academia, se gestó un espacio interactivo virtual multilingüe llamado "Cerebro colectivo", que tiene como principal objetivo conformar una comunidad de aprendizajes y experiencias entre quienes han participado en la Academia (OIT, s.f.b).

En otro caso, y con una orientación similar vinculada a proponer nuevos modelos de desarrollo, CEPAL propone construir un "nuevo futuro" en la región, impulsando una "recuperación transformadora con igualdad y sostenibilidad". En un documento medular al respecto, CEPAL (2020) señala que entre los problemas estructurales del modelo de desarrollo imperante se encuentran el sustancial aumento de la desigualdad (como obstáculo del desarrollo), el empeoramiento de las condiciones de vida de gran parte de la población y el agravamiento de la cuestión ambiental en su dimensión territorial que, en particular, en América Latina y el Caribe (ALyC) conlleva amplias asimetrías de índole geográfica y social. Por ello, postula que una recuperación transformadora requiere de un cambio del modelo de desarrollo que, en línea con las tres dimensiones del desarrollo sostenible (económica, social y ambiental), conjugue el crecimiento económico regional con un sendero de mayor igualdad y sostenibilidad ${ }^{3}$. Para esto, se propone orientar el sistema de regulaciones, políticas públicas e incentivos institucionales hacia un desarrollo más sostenible e igualitario, impulsando una reactivación basada en acciones públicas, sectoriales y transversales que favorezcan la innovación tecnológica y social en esa dirección.

En particular, se presta especial atención a siete ámbitos clave de desarroIlo, entre los que se encuentran: la transición energética hacia energías renovables no convencionales; las políticas de sostenibilidad en movilidad (transporte público y electro-movilidad), viviendas y espacios urbanos; el desarrollo digital sostenible e inclusivo; el impulso al sector de la salud y los encadenamientos vinculados al mismo; la transición agroecológica y la gestión de la biodiversidad de ecosistemas naturales; el desarrollo de la economía circular y de eslabonamientos productivos sostenibles en la gestión de residuos; y la promoción del turismo sostenible. En concreto, nos interesa destacar de dicho planteamiento que CEPAL propone políticas públicas que "ofrezcan espacios para la expansión de la economía social y solidaria, en una lógica de densificación y democratización del tejido productivo" (CEPAL, 2020, p. 213). La proposición es coherente con la reinstalación del tema del cooperativismo y la economía social

3 En tal sentido, define a la "aritmética del desarrollo sostenible" para ALyC, como la combinación de "la tasa de crecimiento necesaria para la igualdad, la de equilibrio externo y la de sostenibilidad ambiental" (CEPAL, 2020, p. 95). 
8 Pandemia, crisis estructural y después ¿qué? Debates sobre desarrollo socioeconómico, territorio y economías alternativas

en la agenda del organismo, así como con el reforzamiento del vínculo institucional al más alto nivel con actores del cooperativismo del continente americano, planteándose una agenda de trabajo en común para la construcción de información, análisis y propuestas por parte del organismo ${ }^{4}$.

Asimismo, siguiendo argumentos más usuales del organismo, el documento postula que es imprescindible el desarrollo de las micro, medianas y pequeñas empresas (MiPyMES) con impacto en la generación de empleo e inserción territorial, reconociendo que las mismas "enfrentan serios problemas de productividad y competitividad" (CEPAL, 2020, p. 213). Pero lo novedoso para el tema que nos ocupa, es que el documento incluye dentro de las MiPyMES tanto a las "privadas", como las que denomina MiPyMES del "sector social", es decir, las cooperativas y otras entidades mencionadas de la ESS. En particular, propone que:

es necesario apoyar el entramado productivo territorial mediante políticas de desarrollo coherentes con las necesidades de las mipymes privadas y del sector social, centradas en la innovación, formación y difusión de conocimientos, la articulación productiva e integración en cadenas de valor, la consolidación de redes asociativas y el fortalecimiento de clústeres locales [...] el acceso a canales de distribución, las plataformas digitales y de insumos básicos, el desarrollo de instrumentos y programas escalables y reproducibles de aprendizaje y crecimiento, el acceso suficiente y en condiciones adecuadas al financiamiento público y privado; las políticas de compras públicas que privilegien las adquisiciones provenientes de las mismas [énfasis añadido]. (CEPAL, 2020, p. 323)

Algunas de estas cuestiones también se vienen considerando en otros organismos multilaterales vinculados a los países desarrollados, tales como la Unión Europea (UE) o la Organización para la Cooperación y el Desarrollo Económico (OCDE), en particular en lo que se refiere a la importancia de la Ess para el desarrollo regional y local. En tal sentido, un reciente documento del programa desarrollo económico y empleo local (LEED) de este organismo, explora este tema desde una perspectiva comparada

4 Además de la visibilidad que la pandemia ha dado a las iniciativas de este tipo, se suma la firma de un acuerdo entre CEPAL y la Alianza Cooperativa Internacional de continente, ACI Américas. A tal efecto el documento de CEPAL define que la economía social y solidaria (ESS) incluye "productores, habilitadores y consumidores", entre las cuales enumera a "cooperativas, asociaciones de consumidores, redes de comercio justo, banca social, ecomonedas, proyectos agroecológicos, iniciativas autogestionadas, uniones de productores rurales, uniones de ejidos y comunidades" (CEPAL, 2020, p. 213). 
entre cuatro países de la UE (OECD, 2020): Francia, España, Suecia y Polonia. El reporte indica que la economía social es un motor de creación de empleo y actividad económica con impacto social, desarrollando sus actividades en una amplia gama de sectores (como banca, seguros, agricultura, salud, servicios sociales y otros), aportando entre el $6 \%$ y el $8 \%$ del PBI en distintos países de la región, así como representando una proporción similar de la ocupación laboral, lo cual significa unos 12 millones de puestos de trabajo para los 27 países de la UE.

A su vez, sostiene que los enfoques de la economía social y el desarrollo local y regional tienen gran potencial de reforzamiento mutuo. En tal sentido, destaca que el afincamiento territorial de la economía social, junto con su orientación a objetivos socio-laborales y ambientales, la gestión democrática y la construcción de redes formales e informales de la misma, son todas cuestiones congruentes con los planteamientos del desarrollo local. En particular, subraya los argumentos vinculados con respecto a la atención de los problemas socioeconómicos y ambientales de los territorios, la preservación y valorización del patrimonio y los activos específicos de los mismos (entre los que incluye la cultura local, la naturaleza, la producción rural y artesanal, etc.), la adaptación de las políticas nacionales o regionales a las necesidades locales, o la construcción de gobernanza democrática para reforzar los procesos de abajo hacia arriba, que permitan ampliar la participación y la construcción de acuerdos y responsabilidades compartidas entre diferentes actores territoriales.

El informe analiza y compara cuatro dimensiones clave para contribuir a fortalecer las estrategias regionales para la economía social y el desarrollo territorial en dichos países: a) el nivel de reconocimiento de la economía social; b) los arreglos de gobernanza multinivel; c) la prioridad estratégica territorial asignada a esta economía; y c) los recursos financieros vinculados a dicha estrategia. En esa dirección, los resultados comparados muestran países con un amplio reconocimiento institucional y normativo de la economía social (España y Francia, en particular), otros en donde esta economía tiene un lugar de interés en agenda de prioridades innovación científica (Suecia y Francia), mientras que en otros casos sobresale su aporte a la creación y diversificación de puestos de trabajo (España), o a la inclusión laboral y ampliación de servicios sociales (Polonia).

En otro plano, el documento considera que las prácticas de economía social basadas en el anclaje territorial, la cohesión social y el desarrollo de oportunidades socioeconómicas para las personas y comunidades, tienen posibilidades de proyectar un impulso global más amplio, por medio del intercambio de experiencias, las redes internacionales, mayor reconocimiento público y social, o la generación de adecuados enfoques y estrategias de desarrollo regional, que reconozcan y acompañen, en mayor 
medida, el potencial de descentralización y de desarrollo de capacidades socioeconómicas, institucionales y territoriales de la misma. Por último, el estudio concluye con algunas consideraciones para mejorar la escala y el alcance de los esfuerzos de políticas regionales de promoción de la economía social, entre los que enumera: un mayor reconocimiento institucional y legal; el desarrollo de capacidades socioeconómicas y empresariales; el financiamiento y apoyo a estrategias y proyectos regionales en economía social; la generación de espacios de intercambio y aprendizajes entre territorios y regiones; el impulso y evaluación de ecosistemas, que incluyan redes territoriales, no solo entre las organizaciones y entidades del sector, sino también con la academia y otros actores sociales de interés, privados o institucionales y el fortalecimiento de los mecanismos de coordinación estratégica entre los mismos.

Para concluir este apartado, hay que tener en cuenta que, por lo general, en los documentos vinculados a organismos internacionales (ONU, OIT y OCDE), cuando se habla de economía social y hasta de ESS, se designa a determinados tipos de empresas $u$ entidades que realizan actividades productivas de bienes, servicios o conocimientos, con impulso solidario y objetivos tanto sociales como económicos. Entre las mismas se mencionan, en particular, a cooperativas, mutuales, asociaciones, fundaciones e incluso empresas sociales (con y sin fines de lucro). Es decir, un campo conformado por entidades sociales y económicas formalizadas, asociativas o de empresas sociales. De allí que esa definición de carácter más institucional, en principio, no incluye otras formas organizativas, territoriales o comunitarias que no estén formalizadas. De igual manera, tampoco lo hace con las iniciativas socioeconómicas de los trabajadores independientes, autónomos, familiares o comunitarios de la economía popular, de creciente importancia en América Latina. Esto nos da pie para ver en el siguiente mensaje internacional de significativa importancia, el planteamiento del Papa Francisco sobre la economía y los movimientos populares.

\section{Crisis y economía (popular) de Francisco}

"De allí el imperativo de escuchar en el corazón y de hacer resonar en la mente el grito de los pobres y de la tierra"

Francisco (2020c)

En su reciente mensaje en la $75^{\circ}$ Asamblea General de la ONU, el Papa Francisco sostuvo que para "garantizar un trabajo digno, hay que cambiar el paradigma económico dominante, que sólo busca ampliar las ganancias de las empresas" (Francisco, 2020a, párr. 8). También recordó su primer mensaje a la Asamblea en 2015 (Francisco, 
2015b), en que expresó su esperanza ante la adopción de la Agenda 2030 para el Desarrollo Sostenible; pero señaló que cinco años después se debía admitir "la poca capacidad de la comunidad internacional para cumplir sus promesas" (Francisco, 2020a, párr. 19). Por ello, recuperando su primer discurso, reiteró la necesidad de evitar un "nominalismo declaracionista con efecto tranquilizador en las conciencias" (Francisco, 2015b, párr. 10).

Estas ideas son reforzadas en su última encíclica, Fratelli Tutti (FT), en la cual afirma que la "sociedad mundial tiene serias fallas estructurales que no se resuelven con parches o soluciones rápidas meramente ocasionales" (Francisco, 2020b, §179). Con mayor énfasis, considera necesario una reforma "tanto de la Organización de las Naciones Unidas como de la arquitectura económica y financiera internacional" (Francisco, 2020b, §173). En particular, como había señalado unos días antes en la Asamblea de la ONU, propone reconsiderar: "el papel de las instituciones económicas y financieras, como las de Bretton-Wods, que deben responder al rápido aumento de la desigualdad entre los súper ricos y los permanentemente pobres" (Francisco, 2020a, párr. 15).

El planteamiento sobre lo insostenible del actual sistema económico está presente en muchos mensajes papales, en los cuales se exhorta a escuchar "el grito de los pobres y de la tierra", como se cita en el epígrafe, pues la crisis es al mismo tiempo social y ambiental, como señaló en noviembre de 2020 en su mensaje al encuentro global que convocó con el nombre de "La economía de Francisco" (EF). Dicho encuentro conectó a miles de jóvenes (estudiantes, emprendedores y economistas) de 115 países del mundo. En este expresó:

apremia otra narración económica, se necesita asumir responsablemente que «el actual sistema mundial es insostenible desde diversos puntos de vista» y golpea principalmente a nuestra hermana tierra, tan gravemente maltratada y expoliada, y a los más pobres y excluidos. Van unidos: tú espolias la tierra y habrá muchos pobres excluidos. Ellos son los primeros afectados... e incluso, los primeros olvidados. (Francisco, 2020c, párr. 3)

De igual manera, el argumento sobre la unicidad de la crisis ya lo había expresado en su anterior encíclica Laudato Si (LS). La primera encíclica social es al mismo tiempo ecológica, pero desde lo que denomina una ecología integral, en que 
Pandemia, crisis estructural y después ¿qué? Debates sobre desarrollo socioeconómico, territorio y economías alternativas

toda pretensión de cuidar y mejorar el mundo supone cambios profundos en «los estilos de vida, los modelos de producción y de consumo, las estructuras consolidadas de poder que rigen hoy la sociedad» (Francisco, 2015a, §5)

no hay dos crisis separadas, una ambiental y otra social sino una compleja crisis socioambiental. Las líneas para la solución requieren una aproximación integral para combatir la pobreza, devolver la dignidad a los excluidos y simultáneamente cuidar el medioambiente. (Francisco, 2015a, §139)

En términos más amplios, hay que tener en cuenta que las encíclicas constituyen un posicionamiento doctrinario de la Iglesia para manifestar, afirmar o ajustar el credo a las circunstancias y transformaciones de una determinada etapa. Las dos de Francisco que hemos citado, forman parte de las Ilamadas "encíclicas sociales", las cuales se fueron sucediendo desde finales del siglo XIX, para abordar temas relacionados con la cuestión social, la paz, la comunicación, el desarrollo, la agricultura, el trabajo, los derechos humanos o la vida humana. Asimismo, en América Latina también sirvieron de inspiración para documentos episcopales o posiciones teológicas críticas, tales como el Documento de Puebla de la III Conferencia General del Episcopado Latinoamericano (1979), o las corrientes latinoamericanas vinculadas a la Teología de la Liberación y su "opción general por los pobres", nacida en la década de 1960 junto con otras iniciativas, como, por ejemplo, las comunidades eclesiales de base. Una cuestión central para los temas de este trabajo, es que estas ideas y experiencias van a estar vinculadas al surgimiento o desarrollo de iniciativas de economía popular o solidaria en numerosos territorios de nuestra región ${ }^{5}$.

En ese recorrido, los planteamientos de Francisco van a posicionar en el centro de la agenda contemporánea a la cuestión socio-ambiental, haciendo hincapié en sus nexos causales con la economía imperante y el poder. Así, recuperando argumentos de la doctrina social de la iglesia, recuerda que "la tradición cristiana nunca reconoció

5 Esta vinculación se observa tanto en trayectorias empíricas como en construcciones simbólicas o conceptuales. Por citar un ejemplo emblemático de este último caso, es pertinente destacar el rol de Cáritas en varios países de Suramérica, impulsando programas de desarrollo en microcrédito, emprendimientos populares o comunitarios, mercados populares o ferias de la economía solidaria. El antecedente más significativo es el caso de Cáritas Brasil, que comenzó a desarrollar programas de apoyo a la "economía popular solidaria" a inicios de la década de 1980 con los llamados "Proyectos Alternativos Comunitarios" (PAC). El desarrollo de esa experiencia significó luego que fuera uno de los actores relevantes en la constitución del movimiento de la economía solidaria en Brasil (Bertucci y Silva, 2004). 
como absoluto o intocable el derecho a la propiedad privada y subrayó la función social de cualquier forma de propiedad" (Francisco, 2020b, §120), reforzando la idea de que

El derecho de algunos a la libertad de empresa o de mercado no puede estar por encima de los derechos de los pueblos, ni de la dignidad de los pobres, ni tampoco del respeto al medio ambiente, puesto que 'quien se apropia algo es solo para administrarlo en bien de todos'. (Francisco, 2020b, §122)

En esa dirección, enuncia que la humanidad aún está lejos de una globalización de los derechos humanos más básicos, remarcando en particular el escándalo de que haya millones de personas con hambre, cuando la "especulación financiera condiciona el precio de los alimentos" (Francisco, 2020b, §189), mientras se desechan toneladas de los mismos. Categóricamente afirma: "El hambre es criminal. La alimentación es un derecho inalienable" (Francisco, 2020b, §189).

En tal sentido, en función del bien común, apela a que la política y la economía "se coloquen decididamente al servicio de la vida, especialmente de la vida humana" (Francisco, 2015b, §189), pues sin la firme decisión de revisar y reformar por entero el sistema, se "reafirma un dominio absoluto de las finanzas" (Francisco, 2015b, §189). En tal sentido, ambas encíclicas ponen el foco del problema en los "poderes económicos" y en el "paradigma tecnocrático" que le es útil:

Los poderes económicos continúan justificando el actual sistema mundial, donde priman una especulación y una búsqueda de la renta financiera que tienden a ignorar todo contexto y los efectos sobre la dignidad humana y el medio ambiente (Francisco, 2015b, §56)

El paradigma tecnocrático también tiende a ejercer su dominio sobre la economía y la política. La economía asume todo desarrollo tecnológico en función del rédito, sin prestar atención a eventuales consecuencias negativas para el ser humano. Las finanzas ahogan a la economía real. (Francisco, 2015b, §109)

Todo ello ocasiona detrimentos en múltiples planos, tales como la destrucción del ambiente, el aumento de las desigualdades, el desempleo, la pobreza, la trata de personas, así como "millones de vidas que se desgarran" como migrantes o refugiados que huyen de la pobreza, las persecuciones o las guerras, mientras que en 
los países de llegada dicha situación suscita alarma, miedo o xenofobia, "a menudo fomentados con fines políticos" (Francisco, 2020b, §39). Y también genera perjuicios en términos subjetivos o culturales, con el predominio del dogma neoliberal vinculado al egoísmo, el culto al individualismo, el lucro a toda costa, o la cultura del descarte.

La cultura del descarte afecta a miles millones de personas y se manifiesta de múltiples maneras: en la exclusión, en la precarización vital, en la "obsesión de reducir los costos laborales" (Francisco, 2020b, §20) sin atender a sus graves consecuencias, en las expresiones de racismo que vuelven a manifestarse abiertamente, por lo cual una amplia parte de la humanidad parece sacrificable (Francisco, 2020b).

Para afrontar todo ello, se necesita "cambiar el modelo de desarrollo global, lo cual implica reflexionar responsablemente sobre el sentido de la economía y su finalidad" (Francisco, 2015b, §194), así como sobre su vinculación con principios éticos. En esa perspectiva, el desarrollo no debe orientase a la creciente acumulación de una minoría, sino "asegurar los derechos humanos, personales y sociales, económicos y políticos" (Francisco, 2020b, §122). Ello requiere de una política económica activa, que favorezca "la diversidad productiva y la creatividad empresarial" (Francisco, 2015b, §129), que aumente los puestos de trabajo y promueva la subsidiaridad, que respalde el desarrollo económico a nivel local, que invierta en educación e infraestructura que beneficie a las comunidades locales, que proporcione las bases para el mejoramiento económico y la renovación de la comunidad (Francisco, 2020a). Para ello, sin caer en localismos "ermitaños", es importante luchar "por lo más concreto y local", que nos hace caminar "con los pies en la tierra", pues "tiene algo que lo global no posee: ser levadura, enriquecer, poner en marcha mecanismos de subsidiaridad" (Francisco, 2020b, §142).

El principio de subsidiaridad garantiza la participación y la acción de las comunidades y organizaciones, que complementan la acción del Estado, permitiendo diversos causes de expresión y de participación social. Y, además, es inseparable para el principio de solidaridad. Hay que cambiar el paradigma económico para que la solidaridad sea un elemento fundamental que reafirme la dignidad y el potencial humano (Francisco, 2020a). Más aún: "el mercado no puede cumplir plenamente su propia función económica" sin formas de solidaridad y de confianza recíproca (Francisco, 2020b, §168). La solidaridad se plantea como valor de pensar y actuar en términos de comunidad, que prioriza la vida, que expresa mucho más que algunos actos aislados de generosidad. La solidaridad como significado ético-político:

También es luchar contra las causas estructurales de la pobreza, la desigualdad, la falta de trabajo, de tierra y de vivienda, la negación de los 
derechos sociales y laborales. Es enfrentar los destructores efectos del imperio del dinero. La solidaridad, entendida en su sentido más hondo, es un modo de hacer historia y eso es lo que hacen los movimientos populares (Francisco, 2020b, §116)

Por ello, en lo fundamental, no alcanzan los paliativos vinculados a modelos más filantrópicos o del tercer sector, más allá de su importancia activa, pues no se trata solo de socorrer necesidades más básicas, sino que es necesario asumir que los pobres tienen la dignidad suficiente para ser partícipes y decisores, para desarrollar sus propias fuerzas, iniciativas y capacidades, entre las que sobresale el trabajo, ya que el "gran tema es el trabajo. Lo verdaderamente popular es el trabajo" (Francisco, 2020b, §162), como camino de maduración, de desarrollo humano, de realización personal, de vida digna (Francisco, 2015b).

De allí la importancia de los movimientos populares, como experiencias de solidaridad que congregan desocupados y trabajadores precarios e informales, y gestan diversas formas de economía popular y producción comunitaria. Para Francisco resulta necesario plantear formas de participación social, política y económica que incluyan dichos movimientos, para animar las estructuras locales y de otros niveles, con "ese torrente de energía moral que surge de la incorporación de los excluidos en la construcción del destino común" (Francisco, 2020b, §169). Esto también significa potenciar la diversidad productiva, que incluye una gran variedad de sistemas alimentarios campesinos y de pequeña escala, que dan alimento a la mayor parte de la población (Francisco, 2015b, §129). En definitiva, impulsar un "desarrollo humano integral" como una política no sólo para, sino sobre todo con los pobres.

En articulación con el Vaticano, en los últimos años se ha gestado un espacio internacional de vinculación entre organizaciones sociales de base, provenientes de cinco continentes, el "Encuentro Mundial de Movimientos Populares". En este confluyen, entre otros, los siguientes movimientos: la Unión de Trabajadores de la Economía Popular (UTEP), de Argentina; La Vía Campesina (Brasil); la Internacional de Asentamientos Informales (Sudáfrica); o el Movimiento Mundial de Trabajadores Cristianos (España). Hasta el presente se han realizado cuatro encuentros con la participación directa de Francisco en los tres primeros: 2014 y 2016 en el Vaticano; y 2015 en Bolivia. A finales de 2020 se efectuó el último encuentro de forma virtual, que contó con la participación de los dos cardenales a cargo del dicasterio para el servicio humano integral. Es decir, que el mismo se realizó muy poco después de la presentación de la encíclica Fratelli Tutti y, en su transcurso, los movimientos presentaron 
el documento consensuado Carta al Papa con motivo del evento "La Economía de Francisco" que, como vimos, se realizó en el mes siguiente.

Dicho documento recoge los planteamientos papales y las conclusiones de los tres encuentros, realizando una propuesta centrada en cinco ejes: a) ecología integral y bienes comunes; b) democracia económica; c) las "tres T": tierra, techo y trabajo; d) educación, salud, comunicación y tecnología; e) soberanía, movilidad humana y paz. Como parte del programa del encuentro, se presentó la Universidad Latinoamericana de las Periferias (ULPE), una iniciativa que se propone construir un proyecto educativo integral y emancipador, impulsado de forma conjunta por la UTEP y la "Familia Grande Hogar de Cristo", una federación de centros barriales territoriales de Argentina, que actúa comunitariamente en villas y asentamientos populares. La propuesta educativa de ULPE tiene como centro las tres T, e incluye como ejes formativos: economía popular, la agroecología y la producción rural comunitaria, ecología integral, o integración sociourbana, entre otras.

En definitiva, estos movimientos dan cuenta de la enorme emergencia de millones de personas de sectores populares en el mundo que, a causa de la exclusión masiva generada por la globalización capitalista del descarte, se ganan la vida generando su propio trabajo, mayormente de alta precariedad, inestabilidad, bajos ingresos, desprotección social y falta de reconocimiento de derechos.

Este proceso tiende a crecer a escala mundial, pero tiene mucha mayor significación en los territorios de la periferia, como en la mayor parte de América Latina. A su vez, la cuestión en nuestra región tiene raíces de más larga data, asociadas a la inserción periférica, dependiente y estructuralmente heterogéneas de nuestras economías y sociedades, a tal punto que fue tematizado desde finales de la década de 1960 con la noción de "masa marginal" (Nun, 1969), para dar cuenta del carácter a/disfuncional de amplios contingentes de trabajadores desocupados, sub-ocupados o con empleos marginales, que ya por esos años comenzaban a incrementarse de manera notoria, ante los problemas del capitalismo periférico para incluir, de manera generalizada, amplias capas de masas populares y de trabajadores mediante relaciones asalariadas estables.

Desde la década de 1980, estos problemas tendieron a expandirse y complejizarse aún más en las formaciones sociales periféricas de América Latina, en el contexto de los cambios estructurales de reordenamiento económico global impregnado por el neoliberalismo, emergiendo otras nociones para analizar la cuestión tal como economía "informal" o "en negro". Por otra parte, en el mismo periodo, otros autores críticos comenzaron a reconocer un fenómeno más amplio y complejo, e introdujeron 
la denominación de "economía popular" para designarlo6 6 incluyendo las iniciativas individuales o familiares, sino también otras experiencias socioeconómicas populares de carácter más comunitario, colectivo o asociativo. La designación se propone, básicamente, quitar la carga negativa de otras denominaciones, reconocer la especificad de funcionamiento de la economía popular que, al estar orientada a la reproducción social, en muchos casos imbrica la economía doméstica con la unidad "productiva", así como visibilizar y valorizar el origen social de los sujetos que impulsan tales iniciativas, rescatando la capacidad de iniciativa, creatividad, organización y movilización de activos socioeconómicos de los sectores populares.

Como veremos a continuación, los aportes desde el desarrollo local o territorial, por lo general, se basan en su vinculación con las entidades de la economía social, de carácter más asociativo e institucional.

\section{Desarrollo territorial y ESS}

Desde otras perspectivas y con argumentos específicos, reconocidas voces académicas del desarrollo territorial vienen planteando críticas y alternativas al modelo de desarrollo hegemónico, partiendo del antecedente de más de una década de debates, propuestas y políticas que vinculan el enfoque del desarrollo local con la economía social.

En efecto, si hasta fines del siglo pasado dicha vinculación era prácticamente inexistente, desde principios del presente el cambio es notable, con una mayor consideración de la economía social en los debates, propuestas y políticas de desarrollo local o territorial, paralelo a la revalorización de la escala local, humana, sostenible e integral del desarrollo, así como de las graves consecuencias de las sucesivas crisis económicas, ambientales o sanitarias como la actual.

Por una parte, desde el punto de vista de las políticas públicas, la economía social se hizo más presente en la agenda del desarrollo local. Un ejemplo de interés en nuestro país, es la creación en el 2003 del denominado Plan Nacional de Economía Social y Desarrollo Local "Manos a la Obra". Este significó una política social novedosa, cuya impronta, si bien parcialmente, persiste hasta el presente, al enlazar lo social

6 Luis Razeto ha sido uno de los primeros y más fructíferos autores que comenzó a hablar de "organizaciones económicas populares", "economía popular" y "economía popular de solidaridad" (Razeto, 1986, 1993). Desde otra perspectiva, también Coraggio (1992) comenzó desarrollar una noción específica sobre economía popular, articulándola luego a sus desarrollo conceptuales de economía del trabajo y economía social (Coraggio 2007, 2016). Una síntesis conceptual muy difundida puede consultarse en el trabajo de Sarria Icaza y Tiribia (2004). 
y lo económico mediante la promoción y apoyo a emprendimientos socio-productivos de sectores populares. Dicho apoyo implica la distribución pública de recursos materiales y monetarios, junto con acciones complementarias para el desarrollo de las capacidades de los destinatarios. En su propuesta original, también incluía espacios de articulación territorial entre actores y gobiernos locales, aunque los resultados a este respecto han sido puestos en duda con argumentos convincentes (Villar, 2007).

Si bien el programa formalmente continúa hasta el presente, fue cambiando en su diseño, importancia y proyección a lo largo del tiempo. En su etapa de principal apogeo (2003-2008), abarcó cientos de miles de productores/as, emprendimientos y trabajadores por cuenta propia e incluyó toda una batería de acciones públicas complementarias, tales como: a) capacitación y tutorías de acompañamiento técnico (2003-2005); b) monotributo social (2004), un instrumento público de formalización subvencionada de "trabajo autónomo", para que puedan facturar y, a la vez, contar con aportes al sistema jubilatorio y a la prestación de servicios de obras sociales ${ }^{7}$; c) microcrédito como política pública (ley 26117/2006), para facilitar y ampliar el acceso crediticio a los sujetos y emprendimientos populares ${ }^{8}$; d) marca colectiva (2008), como línea de acción para mejorar la identidad y la generación de valor agregado en la comercialización.

Para la época, el programa resultó una propuesta novedosa y con aspiraciones más integrales, logrando resultados inmediatos y de escala en cuanto a llegada masiva con recursos, aunque insuficientes ante el carácter estructural y elevada escala de la precariedad y la vulnerabilidad social. Un saldo de importancia es la instalación de la temática socioeconómica en la agenda principal de la política social, dirigida principalmente a los entonces llamados "emprendedores" de la "economía social", fundamentalmente trabajadores independientes y emprendimientos populares, empresas recuperadas y cooperativas autogestionadas, campesinado y agricultura familiar popular, organizaciones socioeconómicas populares y comunitarias. Es decir, en gran medida, los movimientos populares se van a posicionar política y simbólicamente como trabajadores de la "economía popular". Volviendo al programa, son más debatibles los impactos de esta política pública en cuestiones económicas o territoriales orientadas a un cambio más estructural. Algo similar puede señalarse sobre su capacidad para generar organización y tramas colectivas de mayor envergadura,

\footnotetext{
7 Desde el año de su creación (2004) y el último, se encontraban inscritos en él más de 550000 trabajadores entre emprendimientos y cooperativas de trabajo de la economía social.

8 Entre el 2004 y el 2015, se habían otorgado más de 500000 microcréditos en todo el país.
} 
más allá de que también deben reconocerse los esfuerzos y las iniciativas que se intentaron en este sentido.

Desde el punto de vista de los debates sobre el tema, para la misma época algunos análisis hablaron sobre la convergencia entre las visiones y objetivos del desarrollo local y de la economía social, entendiendo a la misma como una estrategia al interior de los procesos de desarrollo local y regional (Altschuler y Casalis, 2006). Desde esta perspectiva, la economía social como una estrategia del desarrollo local, puede contribuir a impulsar procesos de participación y gestión democrática, de mejoramiento de la calidad de vida y satisfacción de las necesidades, o bien caminos colectivos de inclusión social y generación de puestos de trabajo e ingreso. Más necesario aún en contextos nacionales o en comunidades con elevados niveles de pobreza, informalidad, precariedad y vulnerabilidad social, como los que caracterizan a nuestra región.

De forma simultánea, trabajos provenientes de otras latitudes destacaron la capacidad de la economía social para generar tejido socio-productivo y empresarial, particularmente, en los territorios más afectados por problemas socioeconómicos, reconociendo la potencialidad de la misma para forjar procesos de desarrollo endógeno (Mozas Moral y Bernal Jurado, 2006). Los principales los argumentos esgrimidos son similares a los indicados para otros contextos: los efectos sociales positivos de la economía social para generar puestos de trabajo y mejora de ingresos; la conformación de empresas sociales o entidades asociativas a nivel local; el aporte al afincamiento de la población en sus territorios de origen; la posibilidad de satisfacer en mejor medida las necesidades de las personas o las comunidades; la promoción educativa y la cultura local; el desarrollo de relaciones y las tramas socioeconómicas territoriales.

Algunos trabajos indagaron otros aspectos del tipo de vinculación de las organizaciones de la economía social con el territorio, indicando que para éstas el territorio no representa, prioritariamente, un espacio de oportunidad de inversión (como sucede con las grandes empresas lucrativas), sino más bien la base de su actividad y desarroIlo, así como el lugar donde tejen una amplia, intensa y diversa trama de vinculaciones socioeconómicas de proximidad (Colletis, Gianfaldoni y Richez-Battesti, 2005).

Por su parte, Demoustier (2006), señaló que el desarrollo local y la economía social constituían procesos emergentes desde finales del siglo XX, problematizando dos cuestiones: por un lado, señala que la dinámica de renovación organizativa de algunas iniciativas la economía social tendían a asentarse en una base muy micro-local y fragmentada; por otro, preguntando en qué medida se estaba asistiendo a un cambio de paradigma del desarrollo local, que otorgara mayor importancia a la economía 
social o más bien a un crecimiento desterritorializado de algunos tipos de actividades típicamente desarrolladas por esta economía, tales como los servicios a las personas en base a la proximidad del usuario.

Otros trabajos visualizaron a las entidades de Ess como sujetos sociales clave para potenciar la gobernanza territorial, en tanto actores territoriales, que representan intereses colectivos y se basan en principios de acción en común. Pero, a la vez, expresan nuevas necesidades sociales, de igual manera que impulsan, experimentan o desarrollan nuevas iniciativas o formas de organización y gestión socioeconómica anclada en los territorios (Demoustier y Richez-Battesti, 2010).

Una síntesis más reciente (Bastida, Vaquero y Cancelo, 2020), resalta el arraigo territorial de la economía social y el mayor eslabonamiento en relación con otras empresas más desterritorializadas, subrayando, además, su contribución en tres aspectos clave: la generación de riqueza y trabajo; la reinversión de los excedentes en el mismo territorio en que actúa; el desarrollo de capacidades y la ocupación más plena de los recursos locales. Asimismo, se destacó su contribución para fomentar el tejido territorial, así como un acceso más amplio, igualitario y de proximidad a los bienes o servicios. Concluye que la economía social puede ser un agente vertebrador del territorio, dinamizando la producción, el empleo y la generación de valor agregado local.

Por su parte, si volvemos al debate crítico sobre modelos de desarrollo que presentamos previamente, Alburquerque (2020) sostiene que la pandemia y su terrible crisis sanitaria se vincula de manera más profunda con la crisis del tipo de "desarrollo" dominante en el capitalismo contemporáneo, que genera con sus lógicas y circuitos globales de acumulación, no solo graves efectos sociales y ambientales, sino también condiciones favorables para la trasmisión, reproducción y aceleración de virus como la covid (Wallace, Liebman y Chaves, 2020).

Por esto, para la pospandemia no se trata de una recuperación del tipo de crecimiento económico previo, ya que en él radica buena parte del problema, sino en una agenda de reconstrucción que debe ser integral (socioeconómica, ambiental e institucionalmente), resaltando la importancia de la llamada "economía fundamental", la cual está asociada a las infraestructuras para la vida y a los DESC mencionados, en particular, los que se refieren a servicios básicos de carácter universal asociados con los mismos (alimentación, salud, educación, alimentación, cuidado, transporte, hábitat, etc.), incluyendo también los circuitos económicos vinculados a dichos servicios. A nivel territorial, un elemento clave en esa "reconstrucción" es la participación de diversidad de actores socioeconómicos e institucionales en procesos de "gobernanza territorial", entre los cuales se resalta el papel de los actores de la ESS. 
De manera similar, Costamagna (2020) propone una agenda de reflexión sobre el tipo de desarrollo planteado desde lo territorial, recuperando miradas críticas latinoamericanas que tensionen el análisis sobre el mismo, más aún cuando es claro que el modelo actual de desarrollo neoliberal y financiarizado no es sustentable y reproduce inequidades. En ese convencimiento, es clave generar estrategias y herramientas que apunten a una sociedad más igualitaria, concibiendo al territorio como un espacio de disputa y también de construcción social de acuerdos, los cuales pueden girar en torno a proyectos que conjuguen cosmovisiones, modelos y prácticas territoriales transformadoras.

Esto requiere trabajar con perspectivas de derechos y de género, buscando potenciar dinámicas afines en las esferas de la cultura y de la interacción social, al tiempo que desarrollar adecuadas estrategias educativas y enfoques pedagógicos dialógicos, así como políticas territoriales, urbanas y rurales, que sean apropiadas, en temas como desarrollo y acceso al hábitat, servicios públicos locales o infraestructuras materiales y comunicacionales, sean territoriales o comunitarias. Desde el punto de vista económico, esto también requiere avanzar en sistemas productivos locales y en procesos de innovación en el territorio, considerando no solo la innovación tecnológica, sino también la innovación social y de gestión, tanto socioeconómica como institucional. En cuanto a las líneas de acción a priorizar, enumera la producción y el acceso alimentario, el hábitat, el cuidado, la salud comunitaria, el desarrollo de la pequeña producción, el trabajo local, el fortalecimiento de las cadenas productivas regionales.

De una manera integral, esto implica considerar tanto la dimensión productiva y tecnológica local, como la vinculación con los canales y estructuras de circulación territorial, las pautas y condiciones de consumo, el tipo de tecnologías, el uso de energía, el transporte, el tratamiento de residuos, las interrelaciones y agrupamientos socioeconómicos. Estos planteamientos de desarrollo socioeconómico territorial resultan afines a otros que se vienen formulando para la ESS, por ejemplo, los procesos de "acumulación solidaria" (Cruz, 2011, 2020), la construcción de "tramas de valor" (Caracciolo, 2017), o el desarrollo de "circuitos socioeconómicos" (Pastore, 2020).

Un desarrollo territorial de este tipo implica poner a las personas y las comunidades en el centro de la escena, apoyando el desarrollo de las pequeñas y medianas unidades productivas y de la agricultura familiar del territorio. Considera que la ESS 
Pandemia, crisis estructural y después ¿qué? Debates sobre desarrollo socioeconómico, territorio y economías alternativas

tiene un inmenso campo de trabajo en el territorio con sus redes, sus reflexiones, y-al mismo tiempo- un espacio donde las organizaciones sociales y las personas tienen para enseñarle al estado y a la academia, aportando nuevos modelos de producción y de consumo a esta época, cuestionando al capitalismo desde varios frentes. (Costamagna, 2020, p. 10)

En definitiva, como hemos adelantado, se vienen ampliado las voces que señalan los límites del actual modelo de desarrollo y sus repercusiones en los territorios, que plantean la renovación de enfoques y propuestas al mismo, otorgando un lugar de interés a las experiencias alternativas de hacer economía orientada a la sostenibilidad de la vida, entre las cuales se incluye a la economía popular, social o solidaria, dada sus características de finalidad social, vinculación asociativa o comunitaria y anclaje territorial.

En esa dirección, y para concluir el presente trabajo, recuperamos, a continuación, reflexiones y aportes que venimos planteando sobre la temática, realizadas desde un posicionamiento político y epistémico crítico y, a la vez, propositivo, en diálogo e intercambio con otros aportes y debates, que tienen como base nuestra propia experiencia y praxis de desarrollo académico-territorial en ESS, realizado desde una universidad pública de la periferia urbana, popular y heterogénea, de un país del sur de nuestra américa.

\section{Reflexiones finales, recuperando aportes específicos}

Por nuestra parte venimos reflexionando desde hace un tiempo sobre las vinculaciones entre el desarrollo territorial y el amplio campo de las economías populares, sociales y solidarias. El intento ha sido plantear una perspectiva crítica y reflexiva sobre el tema, desde una posición epistémica y política situada que, en lo fundamental, busca contribuir al fortalecimiento y expansión de las economías transformadoras, populares, sociales y solidarias en los territorios.

En conjunto con Altschuler, y a partir de algunos trabajos suyos previos (Altschuler, 2008, 2013; Pastore, 2006, 2014; Altschuler y Pastore, 2014), nuestros argumentos se proponen no reproducir visiones simplistas o ingenuas del desarrollo, en este caso local o territorial, sino problematizar, por el contrario, las propias nociones 
de este, de "territorio" y de sus vinculaciones con la EP y la ESS (Pastore y Altschuler, 2015a; 2015b)

Por una parte, resulta clave recuperar los debates críticos sobre las concepciones economicistas y etnocéntricas del desarrollo, las cuales han planteado como "modelo" a seguir una versión estereotipada del desarrollo capitalista en los países centrales (Pastore y Altschuler 2015a). En otras palabras, recuperar una crítica al desarrollo en tanto construcción discursiva hegemónica, esto es, en tanto discurso de carácter normativo y modernizador, economicista y reduccionista. Contra esta versión del desarrollo como discurso de poder, se han pronunciado distintos tipos de argumentos críticos, que podemos esquematizar en dos grandes corrientes.

De un lado, las perspectivas que buscaron ampliar la noción misma del desarrollo, incorporando una visión multidimensional e integral de mismo, lo cual, en gran medida, supuso adosarle al término una serie de adjetivaciones, tales como "desarro"lo" social, humano, inclusivo, endógeno, sostenible, integral, entre otros, incluyendo también el desarrollo local o territorial. De otro lado, las perspectivas vinculadas a planteamientos más incisivos o radicalizados, según se los considere, que han formulado una crítica más profunda al desarrollo en tanto ideología del "progreso" y de la "modernización", no solo del pasado, sino vigente de forma matizada en el presente. Estas perspectivas, en unos casos recuperan y actualizan la dialéctica del desarrollo-subdesarrollo como dinámica de desigualdad y dependencia; en otros casos, dan visibilidad a lo que ese desarrollo "descarta" y estigmatiza (lo popular, solidario, comunitario o doméstico, por ejemplo); en otros, visibilizan y legitiman "alternativas al desarrollo" y horizontes hacia el "postdesarrollo", como es el caso de las críticas decoloniales al desarrollo (Escobar, 1995; Gudynas, 2011 y 2014)9.

Por otra parte, en relación con la cuestión más local o territorial, hemos puesto en debate algunos planteamientos que trasladaron de forma acrítica enfoques del desarrollo local extra-regionales, por ejemplo, los provenientes de algunos países europeos en las últimas décadas del siglo pasado (Pastore y Altschuler, 2015b). En tal sentido, y a modo de ejemplo, puede señalarse que algunos argumentos iniciales del desarrollo local han otorgado poca consideración a las relaciones de poder, conflicto y correlaciones de fuerza entre grupos sociales y actores en los territorios; cuestión aún de mayor importancia cuando se trata de actores con intereses y visiones ideológicas contrapuestas, y en contextos donde persisten o se profundizan altos niveles de desigualdad, significativas brechas socio-territoriales o estructuras de poder

9 Cumming (2020) realiza un interesante trabajo comparativo de estas perspectivas, en su caso básicamente con la intención de incorporar diversas miradas críticas a la praxis del desarrollo territorial, entre ellas por ejemplo las críticas decoloniales al desarrollo. 
profundamente asimétricas, como ocurre en gran parte de los territorios de nuestra región. De allí también la importancia de concebir al territorio no solo en su dimensión espacial o topográfica, sino particularmente en su dimensión socioeconómica y política, incluyendo su historia, instituciones y estructuras, así como las relaciones económicas y de poder entre sujetos y actores diversos, con objetivos en algunos casos contrapuestos o atravesados por asimetrías y conflictos de envergadura.

En definitiva, consideramos que los procesos socioeconómicos vinculados al desarrollo territorial implican construcciones sociales complejas, que incluyen como horizonte de acción, posibilidades y dinámicas de interacción, el diálogo y los acuerdos amplios en torno a objetivos compartidos, pero que también están surcados por relaciones de fuerza, lucha o disputa (material y simbólica) entre distintos tipos actores, con diversas lógicas de acción, que actúan en estructuras y dinámicas de poder atravesadas por tensiones, conflictos o asimetrías.

Asimismo, las propias características de los procesos socioeconómicos implicados en el desarrollo territorial conllevan dinámicas y relaciones típicamente complejas, que suman a esa condición multi-actoral de acuerdo y conflicto, al menos cuatro características más de complejidad en su carácter de:

- Pluri-dimensional, en tanto procesos que involucran diversidad de ámbitos interelacionados, pero también en tensión, tales como son lo social, lo económico, lo tecnológico, lo político, lo cultural, lo comunitario o lo ambiental.

- Inter-temporal, pues en momentos de crisis como el presente, que son estructurales y recurrentes, se requiere dar una atención prioritaria a la urgencia social, vinculada a procesos más inmediatos o del corto plazo, cuestión muy sensible para la gestión política, más en contextos de disputa. Pero, por lo general, la atención necesaria a la urgencia y lo inmediato, suele estar en tensión con la necesidad de cambios más estructurales, que conlleva actuar sobre intereses y visiones en disputa, que requieren una duración y estabilidad vinculadas al mediano y largo plazo.

- Multi-escalar, implicando procesos organizativos, estructuras y circuitos económicos que van desde lo micro organizativo y espacial, a lo meso territorial (organizativo e interinstitucional), atravesado también por tendencias y dinámicas macrosociales que tienen fuerte impacto en el territorio, sus actores y relaciones.

- Inter-jurisdiccional, como terreno de decisión, intervención y dinámicas de poder entre diferentes niveles y ámbitos de políticas y organismos públicos, tanto nacionales, federales, regionales o locales. 
Todo esto invita a complejizar los análisis y las propuestas de acción orientadas a potenciar el desarrollo socioeconómico territorial, considerando, en particular, los distintos tipos de actores y relaciones vinculadas al mismo, entre los cuales coincidimos en resaltar a los sujetos, emprendimientos y actores de estas economías subalternas con proyección transformadora, que venimos considerando como el campo de las economías populares, sociales o solidarias (Pastore, 2020). Por cierto, este es un campo socioeconómico, simbólico y político de notable dinamismo y diversidad en las últimas décadas, conformado por diversidad de iniciativas surgidas como respuesta a las dinámicas de desigualdad, exclusión y degradación socioambiental que genera el modelo neoliberal dominante, de globalización capitalista, financiarización y acumulación por desposesión (Pastore, 2006, 2014).

Estas alternativas se han expandido en numerosos territorios como opciones de trabajo, generación de ingresos, satisfacción de necesidades o búsqueda de mejora en las condiciones y calidad de vida de las personas y las comunidades. Sus formas organizativas involucran tanto la renovación de las entidades más institucionales e históricas del cooperativismo, el mutualismo y las asociaciones del tercer sector, como el surgimiento de nuevas formas socioeconómicas, populares, solidarias o comunitarias, las cuales no siempre quedan suficientemente reconocidas en los tipos de figuras jurídicas más tradicionales.

De allí que vengan ampliándose sostenidamente en una diversidad de actividades de producción, comercialización, financiamiento, servicios o consumo. Se expanden con las crisis, y es de esperar una nueva oleada al atravesar la actual situación pandémica y sus efectos económicos. Pero no son algo transitorio, sino estructural, y van a seguir multiplicándose como respuesta de las personas, sus organizaciones y comunidades. No son parte del problema, sino de la solución. Deberían dejar de ser desvalorizadas, desconocidas o peor aún, estigmatizadas, por los poderes públicos y por otros actores sociales o movimientos transformadores. De igual manera que deberían ser incorporadas en mayor y mejor medida en los planteamientos académicos, políticos y económicos sobre el desarrollo y el territorio.

Esta interpelación también implica abrir el debate sobre posicionamientos, estrategias y acciones de los actores involucrados o que son favorables a cambios más de fondo y estructurales. En el caso de las empresas y entidades más consolidadas de la economía social, están como punto de partida los planteamientos críticos y transformadores que vienen sosteniendo los máximos espacios de representación del movimiento cooperativo, tal como en los últimos años es el caso de Acl, tanto internacional como ACI Américas para nuestros países. Desde nuestro punto de vista, esto requiere asumir, en mayor medida, una agenda y una práctica efectiva en los 
territorios que actualice y retome de manera el ideario transformador, movimientista e innovador, que representó el surgimiento del movimiento cooperativo, durante el siglo XIX y principios del siglo XX (Singer, 2004). Entre otras cuestiones, esto significa rescatar lo mejor de esa trayectoria cooperativista transformadora, vinculándose de manera más orgánica y participativa con las necesidades de sus comunidades de pertenencia. Dos cuestiones más que nos parecen clave, son: fortalecer estrategias en común con otras organizaciones afines, por ejemplo, en procesos de intercooperación socioeconómica y territorial; impulsar o acompañar iniciativas asociativas y colectivas que promuevan los intereses y proyectos asociativos de los "proletarios", "desposeídos", "descartados" o "precarizados" del siglo XXI, tendiendo puentes para ello con los demás movimientos sociales de idearios afines, en particular, de economía popular y solidaria, de derechos humanos, feminismos y otras luchas socioambientales o territoriales.

Para ello, también es clave el fortalecimiento organizativo y la estrategia política, de lucha, legitimación y reivindicación de derechos, de los trabajadores e iniciativas de la economía popular o solidaria de nuestros países, así como de los movimientos sociales que las sustentan, pero, al mismo tiempo, consideramos fundamental la construcción social de visiones, estrategias y acciones potentes de desarrollo socioeconómico territorial por parte de las mismas, que fortalezcan, por una parte, sus procesos de construcción y disputa de poder, pero también que permitan ampliar sus alianzas sociales y políticas con otras entidades y organizaciones de la ESS y de los trabajadores, con la finalidad de potenciar y proyectar las mismas en el marco de procesos más amplios de democratización y transformación económica de los territorios.

En esa dirección apunta el fortalecimiento y expansión de los procesos organizativos, asociativos y de gestión participativa de estas economías, en el marco de estrategias integrales de fortalecimiento del poder económico, sociopolítico y simbólico de las mismas. En tal sentido, entre otras cuestiones a señalar, se pueden indicar: a) la construcción de valores, identidades y estrategias socioeconómicas compartidas, reconociendo sus singularidades diferenciales; b) el impulso a procesos de organización colectiva, asociatividad, redes y tramas socioeconómicas, sean estas de mercado o comunitarias; c) la asunción de desafíos de una mayor coordinación económica asociativa en los territorios, para ganar escala y sostenibilidad ampliada, impulsando procesos efectivos de "acumulación solidaria", de "tramas de valor" o de "circuitos socioeconómicos"; d) una mejor y mayor vinculación con el sistema educativo y científico-técnico, para impulsar procesos de valorización e innovación socio-técnica de mayor envergadura, en clave de eficiencia colectiva e inter-cooperación. 
Existen múltiples experiencias que muestran que no estamos suponiendo quimeras bien intencionadas ${ }^{10}$, sino prácticas transformadoras en diversos territorios. La diversidad de experiencias de otras formas de organización económica, representado en un sinnúmero de iniciativas económicas populares, sociales y solidarias a lo largo de todo el planeta, dan cuenta de la posibilidad y potencialidad de estas economías en su dimensión empírica. No obstante, también es cierto que las mismas siguen estando en términos estratégicos poco (auto)reconocidas y visibilizadas, así como en gran medida dispersas o fragmentadas.

No podemos dar fe de por sí de su confluencia contra-hegemónica sistémica y menos aún de las factibilidades de construcción efectiva de otros modelos globales, alternativos o de posdesarrollo, pero sentipensamos que la única respuesta ética, intelectual y política que nos resulta coherente, es asumir y acompañar el desafío colectivo, actual e histórico, de los pueblos y de la propia humanidad alzándose contra los sistemas basados en la desigualdad y el dominio, proyectando también en sus luchas, acciones y significaciones, conquistas de derechos y construcción de alternativas transformadoras, entre ellas las de las economías otras, orientadas a la sostenibilidad y reproducción ampliada de la vida. Y estamos dichosos de ser parte de ese camino colectivo de "utopía militante", aquella de la que nos hablara y por la cual lucho Paul Singer, enorme referente latinoamericano de la economía popular solidaria.

\section{Referencias}

Alburquerque, P. (2020). Reflexiones ante el coronavirus desde los territorios: lineamientos para la discusión de una agenda de reconstrucción económica, social, ambiental e institucional. Revista iberoamericana de gobierno local, 7. https://bit.ly/3m0uq54

Altschuler, B. (2013).Territorio y desarrollo: aportes de la geografía y otras disciplinas para repensarlos. Revista THEOMAl, 27-28. https://bit.ly/3meputR

Altschuler, B. (2008). Desarrollo y territorio como ámbitos de disputa: economía social, concentración económica y modelos de acumulación. Anales del $7^{\circ}$ Coloquio de Transformaciones Territoriales. Editorial Esplendor.

10 Diferentes estudios reseñan muchas experiencias transformadoras, entre otros Guerra (2012), Cruz (2020); o Puig y Guride (2020). En particular, este último trabajo recoge experiencias de interés de Europa y América Latina sobre el papel de los territorios en la promoción del emprendizaje y la incubación social en ESs. Otro estudio valioso lo constituye el Proyecto susy (Sustainable and Solidarity Economy), que mapeó experiencias de economía solidaria transformadora en 55 territorios del mundo, fue impulsado por una red de 26 organizaciones en 23 países europeos y apoyado por la UE. 
Pandemia, crisis estructural y después ¿qué? Debates sobre desarrollo socioeconómico, territorio y economías alternativas

Altschuler, B. y Casalis, A. (2006). Aportes del desarrollo local y la economía social a una estrategia nacional de desarrollo. En D. García Delgado y L. Nosetto, (Comps.), El desarrollo en un contexto postneoliberal. Hacia una sociedad para todos (pp. 71-118). cIccus-FLACSO. https:// bit.ly/2WnxvUg

Bastida, M., Vaquero, A. y Cancelo, M. (2020). La contribución de la ley de economía social de Galicia al desarrollo territorial y a la mejora del empleo. Revista de Estudios Cooperativos, 134. https://dx.doi.org/10.5209/reve.69174

Bertucci, A. y Silva, R. (Orgs.). (2004). Veinte años de economía popular solidaria: trayectoria de Cáritas Brasilera de los PAC's a la EPS. Cáritas Brasilera. https://bit.ly/3zFXIAj

Caracciolo, M. (2017). Procesos de acumulación solidaria en un contexto neoliberal. En M. Caracciolo (Coord.), Economía social y solidaria en un escenario neoliberal: algunos retos y perspectivas (pp. 6-19). CEUR-CONICET. https://bit.ly/3CV4iQ5

Chul Han, B. (2021). Teletrabajo, 'zoom’ y depresión: el filósofo Byung-Chul Han dice que nos autoexplotamos más que nunca. El País. https://bit.ly/3kFcrBU

Colletis G., Gianfaldoni P. y RichezBattesti N. (2005). Economie sociale et solidaire, territoires et proximité. Recma, 296, 8-25

Comisión Económica para América Latina y el Caribe (CEPAL). (2021). Panorama Social de América Latina 2020. https://bit.ly/3CKKoaA

Comisión Económica para América Latina y el Caribe (CEPAL). (2020). Construir un nuevo futuro: una recuperación transformadora con igualdad y sostenibilidad. https://bit.ly/3lQ2KzO

Coraggio, J. L. (2016). La economía social y solidaria (ESS): niveles y alcances de acción de sus actores. El papel de las universidades. En C. Puig (Org.), Economía Social y Solidaria: conceptos, prácticas y políticas públicas (pp. 15-40). Universidad del País Vasco/Hegoa.

Coraggio, J. L. (2007). Una perspectiva alternativa para la economía social: de la economía popular a la economía del trabajo. En Coraggio, J. L. (comp.), La economía social desde la periferia. Contribuciones latinoamericanas (pp. 165-194). UNGS/ALTAMIRA.

Coraggio, J. L. (1992). Del sector informal a la economía popular: un paso estratégico para el planteamiento de alternativas populares de desarrollo social. Nueva Sociedad, 131.

Costamagna, P. (2020). Reflexiones y debates sobre el Desarrollo Territorial. Nuevas miradas frente a realidades complejas. Revista RED DETE, 7. https://bit.ly/3zEFMAS 
Cruz, A. (2020). Experiências territoriais de acumulação solidária no Brasil - bancos comunitários e circuitos locais de comercio justo. En J. F. Álvarezy C. Marcuello (Dir.), Experiencias Emergentes de la Economía Social (pp. 290-316). OIBESCOop.

Cruz, A. (2011). La acumulación solidaria. Los retos de la economía asociativa bajo la mundialización del capital. Revista de Estudios Cooperativos, 16(1).

Cummings, A. R. (2020). Desarrollo económico territorial, innovador, inclusivo y regenerativo de ecosistemas. Documento de trabajo. Maestría en Desarrollo Territorial, UCA.

Demoustier, D. (2006). L'économie sociale et solidaire et le développement local. En J. N. Chopart, G. Neyret, D. Rault (Dir.), Les dynamiques de l'économie sociale et solidaire (pp. 115-132). La Découverte.

Demoustier, D. y Richez-Battesti, N. (2010). Les organisations de l'économie sociale et solidaire: gouvernance, régulation et territoire. Géographie, Economie, Société, 12(1), 5-14.

Escobar, A. (1995). Encountering Development. The Making and Unmaking of the Third World. Princeton University Press.

Francisco. (2015a). Encíclica Laudato Si. Sobre el cuidado de la casa común. https://bit.ly/3CIhaJh

Francisco. (2015b). Conferencia en la 75ª Sesión de la Asamblea General de Naciones Unidas. https://bit.ly/3i4Ausr

Francisco. (2020a). El futuro que queremos, las Naciones Unidas que necesitamos: reafirmación de nuestro compromiso colectivo con el multlateralismo. https://bit.ly/3ENN8pf

Francisco. (2020b). Encíclica Fratelli Tutti. Sobre la fraternidad y la amistad social. https://bit. ly/3kByqtA

Francisco. (2020c). Conferencia en La Economía de Francisco. Los jóvenes, un pacto, el futuro. https://bit.ly/3ClpRmJ

Guerra, P. (2012). Miradas globales para otra economía. SETEM.

Gudynas, E. (2014). Las disputas sobre el desarrollo y los sentidos de las alternativas. Revista Kavilando, 6(1), 15-26.

Gudynas, E. (2011). Debates sobre el desarrollo y sus alternativas en América Latina: una breve guía heterodoxa. Más allá del desarrollo, 1, 21-54. 
Pandemia, crisis estructural y después ¿qué? Debates sobre desarrollo socioeconómico, territorio y economías alternativas

Mozas Moral, A. y Bernal Jurado, E. (2006). Desarrollo territorial y economía social. Revista de Economía Pública, Social y Cooperativa, 55, 125-140.

Nun, J. (1969). Superpoblación relativa, ejército industrial de reserva y masa marginal. CEPAL. https://bit.ly/2ZwzsPp

Organización para la Cooperación y el Desarrollo Económicos (OECD). (2020). Regional Strategies for the Social Economy: Examples from France, Spain, Sweden and Poland. OECD Publishing. https://doi.org/10.1787/76995b39-en

Organización de las Naciones Unidas (ONU). (2021). Comisión de Desarrollo Social. Programa provisional anotado y organización de los trabajos propuesta.

Organización Internacional del Trabajo (OIT). (s.f.a). Social and Solidarity Economy. https://bit. ly/3CMVEmS

Organización Internacional del Trabajo (OIT). (s.f.b). Academy on SSE. Home. https://bit.ly/3IQ1AVa

Organización Internacional del Trabajo (ОIT). (2002). R193 - Promotion of Cooperatives Recommendation. https://bit.ly/3ENNsV9

Organización Internacional del Trabajo (OIT). (2008). Declaration on Social Justice for a Fair Globalization. https://bit.ly/3me6QIR

Pastore, R. y Altschuler, B. (2015a). Economía social y solidaria en clave de desarrollo socio-territorial en Argentina. Conceptos, políticas públicas y experiencias desde la Universidad. Eutopía, 7.

Pastore, R. y Altschuler, B. (2015b). La economía social y solidaria, y los debates del desarrollo en clave territorial. Reflexiones sobre experiencias y desafíos a partir de una práctica socioeducativa universitaria. Revista Idelcoop, 217.

Pastore, R. y Altschuler, B. (2014). Economía social y solidaria: un campo socioeconómico, simbólico y político en construcción. Miradas y prácticas desde la Universidad pública. En C. Fidel y A. Villar (Comp.), Miradas y controversias del desarrollo territorial en Argentina. Aproximación a un enfoque analítico. Centro Cultural de la Cooperación-UNQ.

Pastore, R. (2020). Circuitos socioeconómicos y emergencia alimentaria. Una agenda transformadora y democrática para el desarrollo popular y solidario. Revista de ciencias sociales segunda época, 37, 45-62. https://bit.ly/3ocNK1W 
Pastore, R (2014). La economía social y solidaria, una construcción colectiva y plural en el camino de la profundización democrática. En Treinta años de democracia en la Argentina. Universidad Nacional de Quilmes.

Pastore, R. (2006). Diversidad de trayectorias, aproximación conceptual y pluralidad de proyectos de la Economía Social. Documento 54 del Centro de Estudios de Sociología del Trabajo. Facultad Ciencias Económicas, UBA.

Puig, C. y Guridi, L. (2020). El papel de los territorios en el emprendizaje social en Economía Socialy Solidaria. Instituto Hegoa, UPV/EHU.

Razeto L. (1993). De la economía popular a la economía de solidaridad, en un proyecto de desarrollo alternativo. Instituto Mexicano de Doctrina Social Cristiana, https://bit.ly/3u9i1j7

Razeto L. (1986). Economía popular de solidaridad. Identidad y proyecto en una visión integradora. Programa de Economía del Trabajo (PET). https://bit.ly/3EOATsA

Sarria Icaza, A. y Tiribia, L. (2004). Economía Popular. En A. Cattani (Org.), La Otra Economía (p. 441). Editorial Altamira.

Singer, P. (2004). Economía Solidaria. En A. Catani (Org.), La Otra Economía (pp. 199-212). Altamira.

Villar, A. (2007). Políticas municipales para el desarrollo económico-social. Revisando el desarrollo local. Editorial ciccus.

Wallace, R., Liebman, A. y Chaves, L. (2020). Capitalismo y pandemia. covID-19 y los circuitos del capital. La Alianza Global Jus Semper. https://bit.ly/3AMZn3e 